Research Article

\title{
Prediction of Tool Lifetime and Surface Roughness for Nickel-Based Waspaloy
}

\author{
Shao-Hsien Chen ${ }^{1}{ }^{1}$ and Chung-An Y $\mathbf{u}^{2}$ \\ ${ }^{1}$ The Graduate Institute of Precision Manufacturing, National Chin-Yi University of Technology, No. 57, Section 2, \\ Zhongshan Road, Taiping District, Taichung 41170, Taiwan \\ ${ }^{2}$ Department of Mechanical Engineering, National Chin-Yi University of Technology, No. 57, Section 2, Zhongshan Road, \\ Taiping District, Taichung 41170, Taiwan
}

Correspondence should be addressed to Shao-Hsien Chen; e6036@ncut.edu.tw

Received 12 June 2020; Accepted 27 June 2020; Published 27 July 2020

Academic Editor: Jinyang Xu

Copyright $\odot 2020$ Shao-Hsien Chen and Chung-An Yu. This is an open access article distributed under the Creative Commons Attribution License, which permits unrestricted use, distribution, and reproduction in any medium, provided the original work is properly cited.

\begin{abstract}
In recent years, most of nickel-based materials have been used in aircraft engines. Nickel-based materials applied in the aerospace industry are used in a wide range of applications because of their strength and rigidity at high temperature. However, the high temperatures and high strength caused by the nickel-based materials during cutting also reduce the tool lifetime. This research aims to investigate the tool wear and the surface roughness of Waspaloy during cutting with various cutting speeds, feed per tooth, cutting depth, and other cutting parameters. Then, it derives the formula for the tool lifetime based on the experimental results and explores the impacts of these cutting parameters on the cutting of Waspaloy. Since the impacts of cutting speed on the cutting of Waspaloy are most significant in accordance with the experimental results, the high-speed cutting is not recommended. In addition, the actual surface roughness of Waspaloy is worse than the theoretical surface roughness in case of more tool wear. Finally, a set of mathematical models can be established based on these results, in order to predict the surface roughness of Waspaloy cut with a worn tool. The errors between the predictive values and the actual values are $5.122 \% \sim 8.646 \%$. If the surface roughness is within the tolerance, the model can be used to predict the residual tool lifetime before the tool is damaged completely. The errors between the predictive values and the actual values are $8.014 \% \sim 20.479 \%$.
\end{abstract}

\section{Introduction}

In recent years, the development of engine design aims at the applications under high pressure and high temperature, in order to improve the fuel efficiency and to save the related costs. Some parts which adopt stainless steel, aluminum alloys, magnesium alloys, and titanium alloys in the past, such as compressor housings, combustor combustion chambers, and turbine blades, have adopted nickel-based alloys gradually as shown in Figure 1, to meet the requirements of the applications in the special corrosion-resistant environments, high-temperature corrosion environments, or the equipment with hightemperature mechanical strength.
Nickel-based alloys are the alloys containing more than $30^{\circ} \mathrm{wt} \%$ nickel, and the nickel-based parts available on the market often contain more than $50^{\circ} \mathrm{wt} \%$ nickel. Nickel-based alloys were researched and developed in the late 1930s and were first produced by the British in 1941. They support high hardness, high-temperature strength, good thermal stability, and corrosion resistance. They support, especially, better high-temperature resistance than low-alloy steel and stainless steel in case the temperature is higher than $650^{\circ} \mathrm{C}$. In recent years, they have been widely used in aerospace industry, petrochemical industry and other fields. Among these applications, the aerospace industry supports the highest output value accounting for $33 \%$ of the total output value $[2,3]$. 


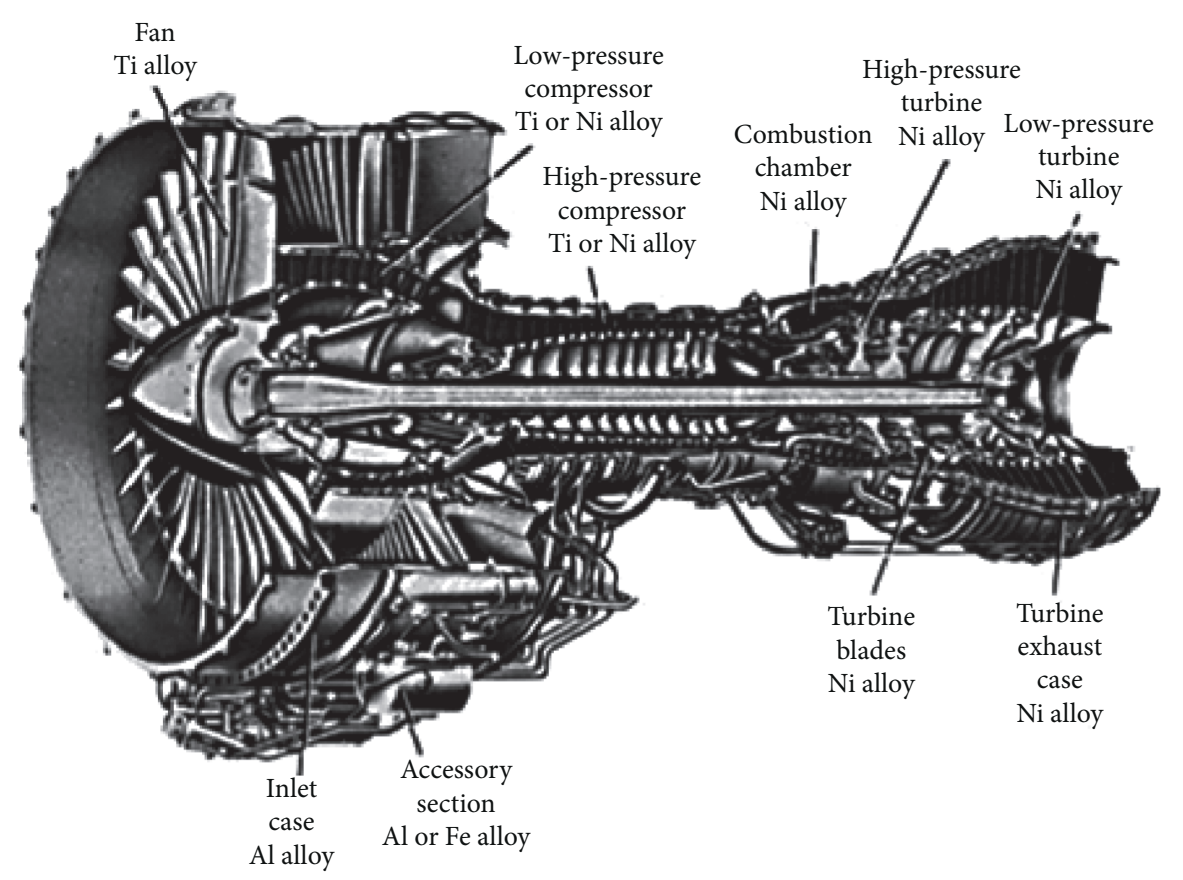

Figure 1: Parts of jet engine [1].

Hanasaki et al. [4] discovered that the coated tool supports better resistance on the groove wear and the tool wear when cutting a nickel-based alloy with a tungsten carbide tool with a specific coating. They also pointed out that the tool lifetime depends on the tool chipping and the adhesion wear during the low-speed cutting and depends on the wear caused by the tool temperature increases during the high-speed cutting.

In the research on the cutting Inconel-718 alloy with ceramic tools and ceramic tools, Nalbant [5] figured out that carbide tools are more suitable then ceramic tools for cutting Inconel-718 alloy. According to the comparison of different cutting speeds, they discovered that ceramic tools are suitable for high-speed cuttings, and carbide tools are suitable for low-speed cuttings. Moreover, the cutting force is inversely proportional to the cutting speed.

Jawaid et al. [6] explored the cutting performance and the wear resistance of tungsten carbide tools with and without TiN coating on the face milling of Inconel-718 alloy.

Zetek et al. [7] cooled down and changed the tool angle with the cutting fluids to cut Inconel-718 alloys. The tool lifetime was improved by $35 \%$ by improving the tool geometrical shape.

After applying the Ti-based and Cr-based metal tool coated with diamond-like films to mill aluminum alloys, $\mathrm{X}-\mathrm{H}, \mathrm{W}$ ang and $\mathrm{Su}$ [8] figured out that the surface roughness is worse than those milled with tools without coating. However, the tool wear is better, and this of Cr-based metal tools is better than this of Ti-based metal tools.

The thesis on machining mostly issue on tool wear and optimization parameter, this study mainly objects at the simultaneous prediction of tool wear and surface roughness to specifically for the nickel-based alloy Waspaloy.

\section{Cutting Principle and Material Property}

2.1. Cutting Property of Nickel-Based Materials. Waspaloy is one of the nickel-based alloys and contains about fifteen alloy elements. Among these elements, the additional aluminum (Al) and chromium ( $\mathrm{Cr}$ ) can improve the hightemperature oxidation resistance, the additional chromium (Cr) and titanium (Ti) can prevent hot corrosion caused by sulfides, and other elements also can provide corresponding features. After the aging treatment, nickel-based alloys will coherently precipitate the fine spherical $\gamma^{\prime}$-phase on the base ( $\gamma$-phase) of the face-centered cubic (FCC) and then generate the coherency strain. The generation of $\gamma^{\prime}$-phase affects the high-temperature properties of nickel-based alloys, and more generations cause better high-temperature properties. Moreover, the solidified aluminum (Al) and titanium (Ti) contribute to the generation of the $\gamma^{\prime}$-phase, and cobalt (Co) can increase the $\gamma^{\prime}$-phase melting temperature and raise the high-temperature strength and stability. Because Waspaloy contains more aluminum ( $\mathrm{Al}$ ) and titanium (Ti), it has more $\gamma^{\prime}$-phase, and better high-temperature strength, creep, oxidation, and corrosion resistance. However, it also causes more processing difficulties $[9,10]$.

The increase of the $\gamma^{\prime}$-phase precipitations enhances both the tensile strength and the falling strength of the alloy but reduces the toughness. In addition, the carbon elements contained in the alloy also cause the absolute influences on the properties of the nickel-based alloy. Carbon does not combine with nickel to form carbides, but it can combine with other alloy elements to form intermetallic compounds. The carbides that precipitated from nickel-based alloys are MC, $M_{6} C, M_{7} C_{3}$, and $M_{23} C_{6}$ as shown in Figure 2. Material scientists discovered that MC (high-temperature tungsten 
carbide phase) would be precipitated in the form of a mass, which is not beneficial for alloy materials and $M_{6} C$ is often precipitated at the grain boundary in the form of a mass to control the grain size. Moreover, $M_{7} C_{3}$ will be generated in the intervals between crystal grains. If it is discontinuously distributed, it will strengthen the alloy material. On the contrary, if it is precipitated at the grain boundaries, it may cause the embrittlement of the alloy.

The toughness of Waspaloy is relative to the precipitated carbides at the forging deformation grain boundary, the large-angle recrystallization grain boundary, and the deformation twin rather than the size and distribution of $\gamma^{\prime}$-phase. At above the $\gamma^{\prime}$-phase dissolution temperature (above $1080^{\circ} \mathrm{C}$ ), $\mathrm{MC}$ will be autolysis. During the subsequent solid solution process, the $\mathrm{MC}$ precipitations result in a twin structure and may generate a carbide film at the grain boundary. The content of major elements in the hightemperature superalloys leads to a great influence on microstructure, structural stability, and final properties. In the production process, the content of major elements in the $\gamma^{\prime}$-phase and the carbide may be not the same, and their precipitation quantities, precipitations, and solid solution temperature may also be different. $[12,13]$.

2.2. Strengthening Mechanism of Waspaloy Superalloy. Nickel-based alloys have good strength and ductility at medium and low temperatures. The strengthening factors come from a combination of various mechanisms, including the solid solution strengthening, the precipitation strengthening, and the grain boundary strengthening as the following summarization [14-16].

2.2.1. Austenitic-Base Solid Solution Strengthening. Since the alloy contains about $\mathrm{Cr}$ and $\mathrm{Mo}$ and the atomic volumes of $\mathrm{Cr}$ and $\mathrm{Mo}$ are both larger than this of $\mathrm{Ni}$, the substitutional solid solution will be generated when the alloy is solid solubilized in the base. Then, the grain lattice of base will be distorted to generate the strain and the strengthening effect.

2.2.2. $\gamma^{\prime}$-Phase Precipitation Strengthening. The precipitation strengthening is relative to the interaction between the precipitation phase and the dislocation. Since the $\gamma^{\prime}$-phase is regular and coherent precipitates, the strengthening effect on the precipitates is generally caused by the inversed phase boundary and defect hardening when the dislocation generates precipitates, the proportion of size and the volume of precipitates affects the important factors of the coherency strain.

2.2.3. Grain Boundary Strengthening. It is the strengthening effect caused by the precipitating carbides generated at the grain boundary to block the grain boundary sliding. A small amount of boron (B) segregates the precipitated carbides at the grain boundary and reduces the grain boundary diffusion. Also, the grain size and direction can be controlled to generate the strengthening effect. In case of the higher creep resistance of fine grain at the medium temperature and high stress, the control factor of creep is the dislocation sliding. In case of the higher creep resistance of coarse grain at the high temperature and low stress, the control factor of creep is the dislocation climbing. The main precipitation strengthening mechanism in the nickel-based alloy is $\gamma^{\prime}$. This mechanism and the coherency strain generated in the base support higher strength for the nickel-based alloy at the medium or low temperature environment.

\subsection{Cutting Principle}

2.3.1. Tool Life and Wear. The experiment method used in this research is face milling. For the tool lifetime predictions and cutting research, the feed per tooth, cutting speed, and depth are the essential cutting parameters. Since a disposable insert of circular is adopted in the cutting process, the feed per tooth and the cutting depth are relative, as shown in Figure 3. Thus, the feed per tooth is calculated as follows $[17,18]$ :

$$
\begin{aligned}
f_{z} & =\frac{H_{e x} C_{i}}{2 \sqrt{a_{p} C_{i}-a_{a}^{2}}}, \\
a_{p}^{2}-C_{i} a_{p}+\left(\frac{H_{\mathrm{ex}} C_{i}}{2 f_{z}}\right)^{2} & =0 .
\end{aligned}
$$

Generally, the cutting tool lifetime research is divided into qualitative method and quantitative method. The research adopts the quantitative method for the investigations and analysis mainly. In each set of the cutting parameters, the total travel length is $1410 \mathrm{~mm}$. For each $282 \mathrm{~mm}$, the tool wear and the surface roughness are measured for each $282 \mathrm{~mm}$. Therefore, there are 5 values of the tool wear and the surface roughness for each set of the cutting parameters. Based on these measurement results, the tool lifetime for each set of the cutting parameters can be derived at the tool wear $\mathrm{VB}=0.3 \mathrm{~mm}$, and then it can be substituted into the formula as follows $[19,20]$ :

$$
V \times T^{n} \times f_{z}^{a} \times \mathrm{ap}^{b}=C .
$$

Substitute the known values of the cutting speed, $V_{1}, V_{2}$, and $V_{3}$; the feed per tooth, $f_{z 1}, f_{z 2}$, and $f_{z 3}$; cutting depth, $\mathrm{ap}_{1}$, $\mathrm{ap}_{2}$, and $\mathrm{ap}_{3}$; and tool lifetime, $T_{1}, T_{2}$, and $T_{3}$ into the above formula:

$$
\left\{\begin{array}{l}
V_{1} T_{1}^{n} f_{z 1}^{a} \mathrm{ap}_{1}^{b}=C, \\
V_{2} T_{2}^{n} f_{z 2}^{a} \mathrm{ap}_{2}^{b}=C, \\
V_{3} T_{3}^{n} f_{z 3}^{a} \mathrm{ap}_{3}^{\mathrm{b}}=C .
\end{array}\right.
$$

Since the previous formula with each set of the cutting parameters can derive a constant value $C$, it can be derived as follows:

$$
V_{1} T_{1}^{n} f_{z 1}^{a} \mathrm{ap}_{1}^{b}=V_{2} T_{2}^{n} f_{z 2}^{a} \mathrm{ap}_{2}^{b}=V_{3} T_{3}^{n} f_{z 3}^{a} \mathrm{ap}_{3}^{b} .
$$

After the further derivations, the cutting parameters, feed per tooth, cutting speed, and depth are proportional and can be presented as follows: 


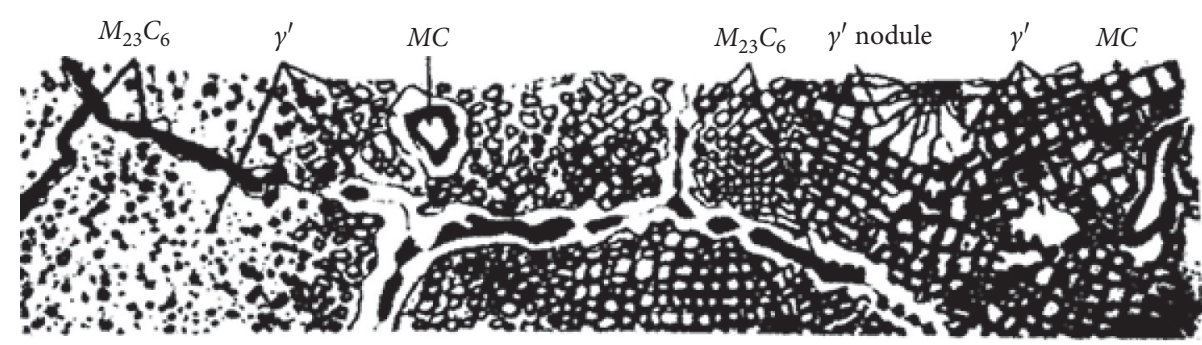

Figure 2: Grain structure of nickel-based materials [11].

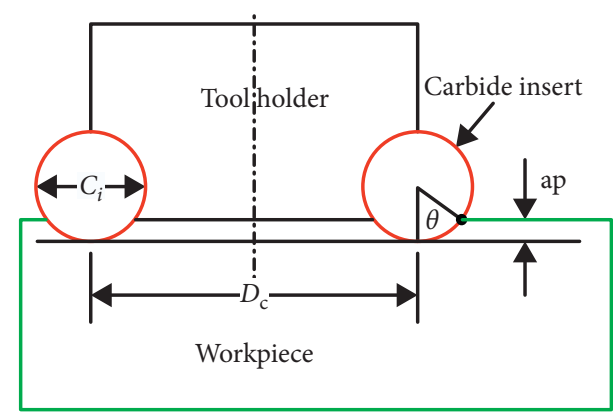

Figure 3: Geometry and labeling of a cutting tool.

$$
\left\{\begin{array}{l}
\left(\frac{T_{1}}{T_{2}}\right)^{n}\left(\frac{f_{z 1}}{f_{z 2}}\right)^{a}\left(\frac{\mathrm{ap}_{1}}{\mathrm{ap}_{2}}\right)^{b}=\frac{V_{2}}{V_{1}} \\
\left(\frac{T_{2}}{T_{3}}\right)^{n}\left(\frac{f_{z 2}}{f_{z 3}}\right)^{a}\left(\frac{\mathrm{ap}_{2}}{\mathrm{ap}_{3}}\right)^{b}=\frac{V_{3}}{V_{2}} \\
\left(\frac{T_{1}}{T_{3}}\right)^{n}\left(\frac{f_{z 1}}{f_{z 3}}\right)^{a}\left(\frac{\mathrm{ap}_{1}}{\mathrm{ap}_{3}}\right)^{b}=\frac{V_{3}}{V_{1}}
\end{array}\right.
$$

Rewrite the above formula in a matrix as follows:

$$
\left[\begin{array}{l}
\ln \left(\frac{T_{1}}{T_{2}}\right) \ln \left(\frac{f_{z 1}}{f_{z 2}}\right) \ln \left(\frac{\mathrm{ap}_{1}}{\mathrm{ap}_{2}}\right) \\
\ln \left(\frac{T_{2}}{T_{3}}\right) \ln \left(\frac{f_{z 2}}{f_{z 3}}\right) \ln \left(\frac{\mathrm{ap}_{2}}{\mathrm{ap}_{3}}\right) \\
\ln \left(\frac{T_{1}}{T_{3}}\right) \ln \left(\frac{f_{z 1}}{f_{z 3}}\right) \ln \left(\frac{\mathrm{ap}_{1}}{\mathrm{ap}_{3}}\right)
\end{array}\right]\left[\begin{array}{l}
\ln \left(\frac{V_{2}}{V_{1}}\right) \\
a \\
b
\end{array}\right]=\left[\begin{array}{l}
\ln \left(\frac{V_{3}}{V_{2}}\right) \\
\ln \left(\frac{V_{3}}{V_{1}}\right)
\end{array}\right] .
$$

Based on the previous formula, the variables, $n, a$, and $b$ and each set of the cutting parameters can be derived and substituted into formula (3) for the constant value $C$, and then the formula of tool lift-time on the cutting of superalloy, Waspaloy, can be derived finally. Also, the impacts of cutting parameters on the cutting of superalloy, Waspaloy, can be derived based on the formula of tool lift-time.

The machining time required for the tool to reach flank wear, mainly for continuous cutting test of single blade and then the tool wear process, is (1) initial wear rate, (2) uniform wear rate, and (3) accelerating wear rate, for uniform wear is
$0.3 \mathrm{~mm}$ and nonuniform wear is $0.6 \mathrm{~mm}$ (tool life criterion); this study is based on the ISO-8688-1/1994 standard for testing and analysis.

2.3.2. Tool Wear and Surface Roughness. For most of the sets of cutting parameters, the actual surface roughness is less than the theoretical one. The theoretical surface roughness can be defined as the surface roughness under conditions of a complete tool. However, the cutting of a worn tool is a straight-line as shown in Figure 4(b) rather than a circular arc as shown in Figure 4(a). Moreover, the surface roughness generated by a worn tool is less than the theoretical one based on Figure 4. Thus, the straight-line generated by the tool shape will be impacted by the tool wear as shown in Figure 5 . The surface roughness is relative to the feed per tooth in accordance with the surface roughness theory, the feed per tooth in the first set of cutting parameters is $0.3 \mathrm{~mm} /$ tooth, and the straight-line $(C 2)$ caused by the tool wear is much more than the feed per tooth. Therefore, the tool wear and the shape of worn tool may impact the surface roughness in addition to the feed per tooth in this experiment.

The tool wear and the surface roughness are relative. Thus, the tool wear straight-line is calculated as follows:

$$
\begin{aligned}
a & =V B \times \tan 7^{\circ}, \\
b & =R-a \\
C 1 & =\sqrt{R^{2}-b^{2}}, \\
C 2 & =2 C 1,
\end{aligned}
$$

where $\mathrm{VB}$ is the tool wear $(\mathrm{mm})$ and $R$ is the radius of tool (fixed value: $6 \mathrm{~mm}$ ).

\section{Experimental Procedure and Equipment}

3.1. Experimental Plan. The research contains the variable factors, resolution, cutting depth, and feed rate and adopts the disposable insert tool coated TiAlN to perform the experiment. Through the generalized formula of tool lifetime and the substitution of a set of cutting parameter into the formula to derive the constant value $C$, the formula of tool lift-time on the cutting of superalloy, Waspaloy, can be derived finally. Moreover, the relations between surface roughness and the tool wear can be established through the formula of surface roughness, and the impacts of cutting 

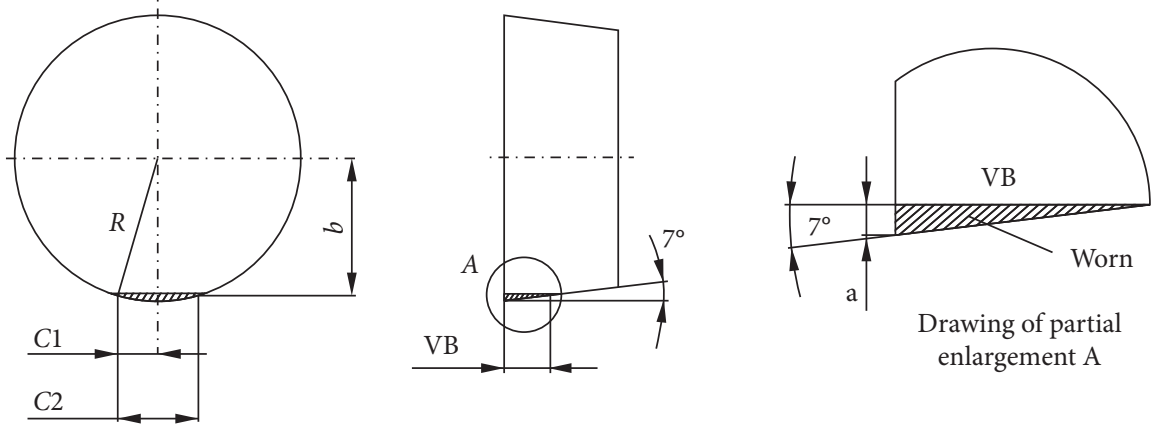

FIGURE 4: Effects of tool wear on surface roughness.

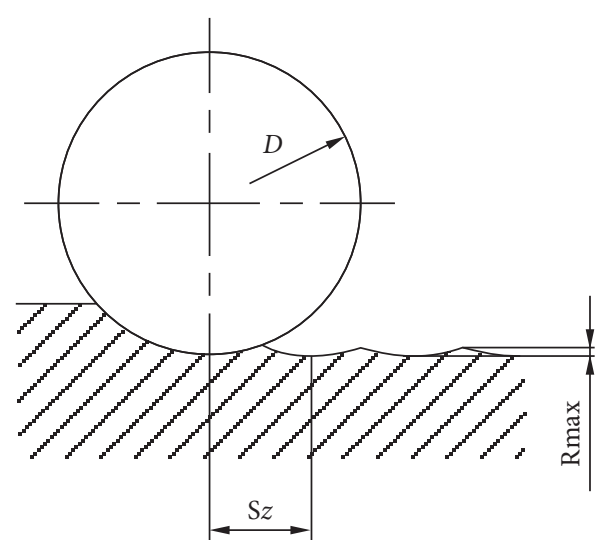

(a)

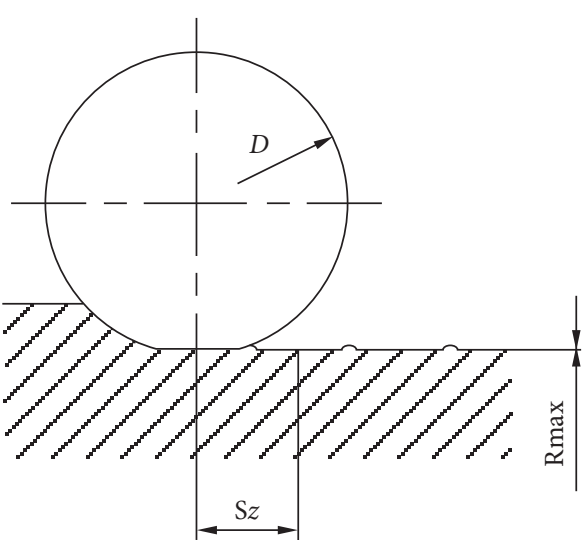

(b)

Figure 5: Effects of tool wear on tool shape. (a) Surface roughness of complete tool. (b) Surface roughness of worn tool.

parameters on the cutting of superalloy, Waspaloy, can be derived based on the formula of tool lift-time. This experiment adopts the cutting speed, the feed per tooth, and the cutting depth as the variables in accordance with the recommendations of the tool catalog on the cutting of nickelbased alloy, such that the cutting speed $(\mathrm{Vc})$ is $40 \sim 36.5(\mathrm{~m} /$ $\mathrm{min}$ ) and the feed per tooth (fz) is $0.28 \sim 0.42(\mathrm{~mm} /$ tooth). The experimental procedure is described in Figure 6 and Table 1.

\section{Result and Discussion}

4.1. The Relationship between Tool Wear and Time. The cutting experimental results show the tool wear is more with the longer cutting travel length or the cutting time. The tool lifetime aims to explore the relations between the cutting time and tool wear, and this experiment observes the impacts of cutting travel length on the tool wear. Therefore, the travel length can be converted into the cutting time in the following tables and figures. In addition, the feed rate $(F)$ can be derived based on the cutting conditions mentioned. The cutting travel length is directly proportional to the cutting time and inversely proportional to the feed rate.

The cutting parameters adopted in the first experiment for tool wear are the cutting speed $(V)=40 \mathrm{~m} / \mathrm{min}$, the feed per tooth $(\mathrm{fz})=0.3 \mathrm{~mm} /$ tooth, the cutting depth $(\mathrm{ap})=0.3 \mathrm{~mm}$, and the travel length $(L)=282 \mathrm{~mm}, 564 \mathrm{~mm}, 846 \mathrm{~mm}, 1128 \mathrm{~mm}$, and $1410 \mathrm{~mm}$. As shown in Figure 7, the longer travel length will increase the tool wear. It is caused by the effects of tool usage mainly.

Based on the experimental results, the relations between time and tool wear can be drawn as shown in Figure 7. With the method of least squares, a curve approaching the experimental point can be derived, and the formula of fitting curve can be described as follows:

$$
V B=0.084 \times e^{0.157 t} .
$$

Through the above formula, at the $0.3 \mathrm{~mm}$ of tool wear (i.e., $\mathrm{VB}=0.3$ ), the time is $8.108 \mathrm{~min}$. It is the tool lifetime $(T)$ under conditions of the first cutting parameters, where VB is tool wear $(\mathrm{mm})$ and $t$ is the cutting time ( $\mathrm{min})$.The cutting parameters adopted in the second experiment for tool wear are the cutting speed $(V)=37.5 \mathrm{~m} / \mathrm{min}$, the feed per tooth $(\mathrm{fz})=0.35 \mathrm{~mm} /$ tooth, the cutting depth $(\mathrm{ap})=0.25 \mathrm{~mm}$, and the travel length $(L)=282 \mathrm{~mm}, 564 \mathrm{~mm}, 846 \mathrm{~mm}, 1128 \mathrm{~mm}$, and $1410 \mathrm{~mm}$ as shown in Figure 8 .

Based on the experimental results, the relations between time and tool wear can be drawn as Figure 8 . With the method of least squares, a curve approaching the experimental point can be derived, and the formula of fitting curve can be described as follows:

$$
V B=0.066 \times e^{0.177 t} .
$$

Through the above formula, at the $0.3 \mathrm{~mm}$ of tool wear (i.e., $\mathrm{VB}=0.3$ ), the time is $8.544 \mathrm{~min}$. It is the tool lifetime $(T)$ under conditions of the second cutting parameters. The 


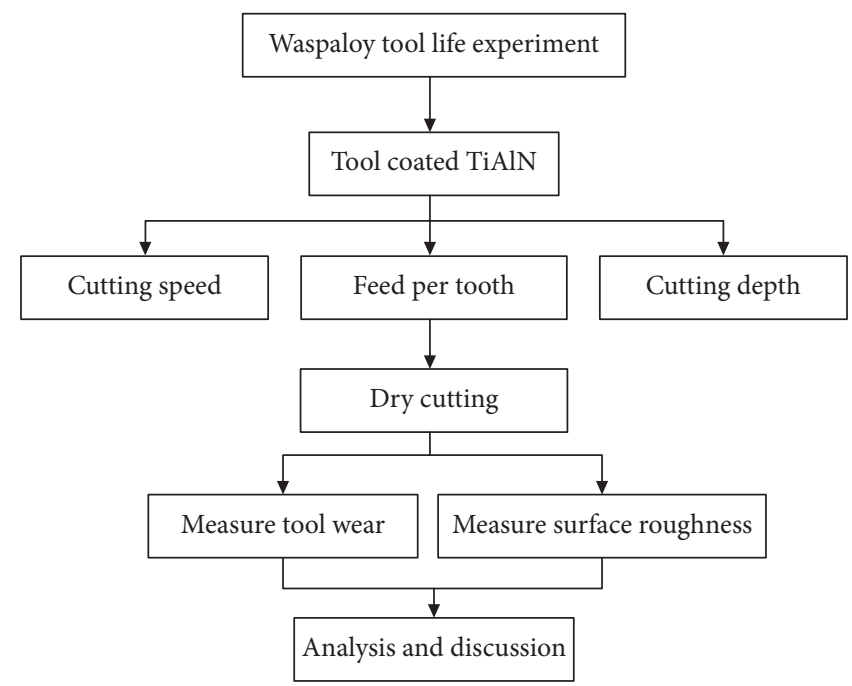

Figure 6: Experimental procedure.

Table 1: Cutting condition design.

\begin{tabular}{lccc}
\hline Parameter set no. & Cutting speed $(\mathrm{m} / \mathrm{min})$ & Feed per tooth $(\mathrm{mm} /$ tooth $)$ & Cutting depth $(\mathrm{mm})$ \\
\hline 1 & 40 & 0.3 & 0.3 \\
2 & 37.5 & 0.35 & 0.25 \\
2 & 35 & 0.4 & 0.2 \\
\hline
\end{tabular}

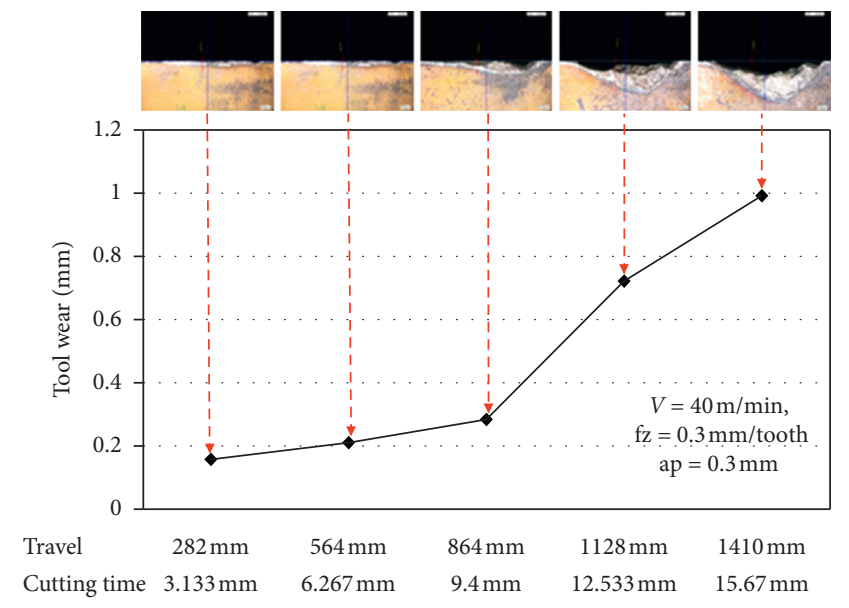

FIgUre 7: Tool wear under conditions of $V=40 \mathrm{~m} / \mathrm{min}$, $\mathrm{fz}=0.3 \mathrm{~mm} /$ tooth, and $\mathrm{ap}=0.3 \mathrm{~mm}$.

cutting parameters adopted in the third experiment for tool wear are the cutting speed $(V)=35 \mathrm{~m} / \mathrm{min}$, the feed per tooth $(\mathrm{fz})=0.4 \mathrm{~mm} /$ tooth, the cutting depth $(\mathrm{ap})=0.2 \mathrm{~mm}$, and the travel length $(L)=282 \mathrm{~mm}, 564 \mathrm{~mm}, 846 \mathrm{~mm}, 1128 \mathrm{~mm}$, and $1410 \mathrm{~mm}$ as shown in Figure 9.

Based on the experimental results, the relations between time and tool wear can be drawn as in Figure 9. With the method of least squares, a curve approaching the experimental point can be derived, and the formula of fitting curve can be described as follows:

$$
\mathrm{VB}=0.081 \times e^{0.119 t} \text {. }
$$

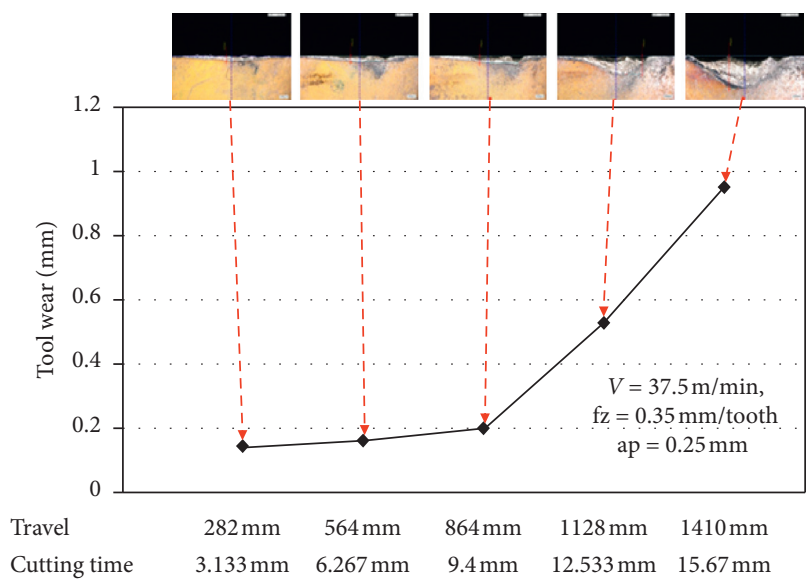

FIgURE 8: Tool wear under conditions of $V=37.5 \mathrm{~m} / \mathrm{min}$, $\mathrm{fz}=0.35 \mathrm{~mm} /$ tooth, and $\mathrm{ap}=0.25 \mathrm{~mm}$.

Through the above formula, at the $0.3 \mathrm{~mm}$ of tool wear (i.e., $\mathrm{VB}=0.3$ ), the time is $11.003 \mathrm{~min}$. It is the tool lifetime (T) under conditions of the third cutting parameters. Summarily, the above experimental results can be listed in Table 2.

Substituting all known values into formula (3) and calculating the matrix can derive the results: $n=0.036$, $a=0.302$, and $b=-0.088$. Substituting these values into formula (5) can derive the formula as follows:

$$
\mathrm{VT}^{0.036} \mathrm{fz}^{0.302} \mathrm{ap}^{-0.088}=C \text {. }
$$




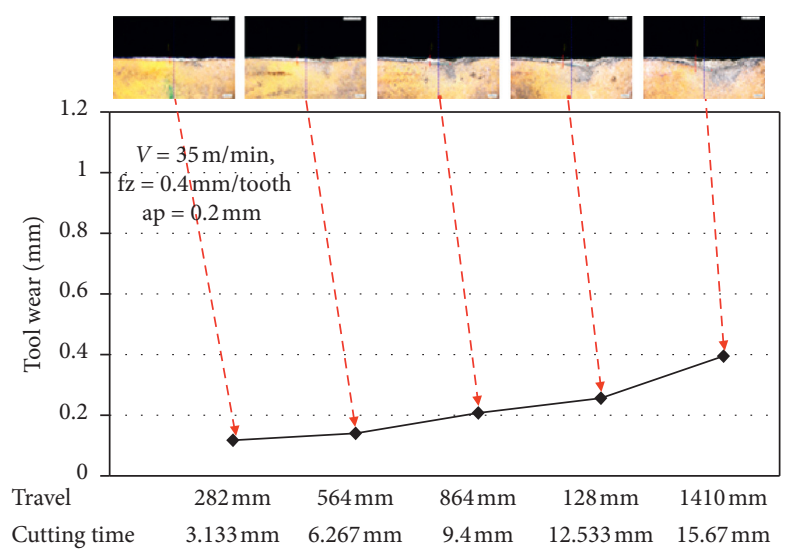

FIgURE 9: Tool wear under conditions of $V=35 \mathrm{~m} / \mathrm{min}, \mathrm{fz}=0.4 \mathrm{~mm} /$ tooth, and ap $=0.2 \mathrm{~mm}$ (conti.).

TABLE 2: Tool lifetime for cutting parameters.

\begin{tabular}{lcccc}
\hline Parameter set no. & Cutting speed $(\mathrm{m} / \mathrm{min})$ & Feed per tooth $(\mathrm{mm} /$ tooth $)$ & Cutting depth $(\mathrm{mm})$ & Tool lifetime $(\mathrm{min})$ \\
\hline The first group & 40 & 0.3 & 0.3 & 8.108 \\
The second group & 37.5 & 0.35 & 0.25 & 8.554 \\
The third group & 35 & 0.4 & 0.2 & 11.003 \\
\hline
\end{tabular}

Substituting the first set of cutting parameters, including the cutting speed $(V)$, feed per tooth (fz), cutting depth (ap), and tool lifetime $(\mathrm{T})$, into the above formula can derive the constant value $C=33.334$. Finally, the formula for tool lifetime can be derived as follows:

$$
\mathrm{VT}^{0.036} \mathrm{fz}^{0.302} \mathrm{ap}^{-0.088}=33.334
$$

4.2. Experimental Parameters and Significant Factor Analysis. Based on the formula of tool lifetime, the relations between the cutting speed $(V)$ and the tool lifetime $(T)$ can be derived when the feed per tooth (fz) and the cutting depth (ap) are set to 1 . Similarly, the relations between the feed per tooth and the tool lifetime and between the cutting depth and the tool lifetime can also be derived. These procedures can be described as follows [20]:

$$
\left\{\begin{array}{l}
\mathrm{fz}=1, \text { ap }=1 \\
V=1, \text { ap }=1 \\
V=1, \mathrm{fz}=1
\end{array}\right.
$$

They are substituted into formula (16):

$$
\begin{gathered}
\Longrightarrow\left\{\begin{array}{l}
V T^{0.036}=33.334, \\
T^{0.036} f z^{0.302}=33.334, \\
T^{0.036} a p^{-0.088}=33.334,
\end{array}\right. \\
\Longrightarrow\left\{\begin{array}{l}
\ln (V)+0.036 \ln (T)=3.507, \\
0.036 \ln (T)+0.302 \ln (\mathrm{fz})=3.507, \\
0.036 \ln (T)-0.088 \ln (\mathrm{ap})=3.507,
\end{array}\right.
\end{gathered}
$$

$$
\Longrightarrow\left\{\begin{array}{l}
\ln (T)=-27.778 \ln (V)+97.417 \\
\ln (T)=-8.389 \ln (\mathrm{fz})+97.417 \\
\ln (T)=2.444 \ln (\mathrm{ap})+97.417
\end{array}\right.
$$

According to formula (20), $\ln (T)$ will be reduced 27.778 when $\ln (V)$ increases 1 . That is, $T$ will be multiplied by $8.633 \times 10^{-13}$ when $\ln (V)$ increases 1 . Second, $\ln (T)$ will be reduced 8.389 when $\ln (\mathrm{fz})$ increases 1 . That is, $T$ will be multiplied by $2.274 \times 10^{-4}$ when $\ln (\mathrm{fz})$ increases 1 . Third, $\ln (T)$ will be reduced 2.444 when $\ln (\mathrm{ap})$ increases 1 . That is, $T$ will be multiplied by 11.519 when $\ln ($ ap) increases 1 . Based on these results, the larger slope of the formula leads to more impacts on the tool lifetime. Therefore, the impacts of the cutting speed on the cutting of Waspaloy are larger, and the impacts of the cutting depth are smaller as shown in Figure 10.

4.3. Relations between Tool Wear and Surface Roughness. As the experimental procedure, not only the tool wear but also the surface roughness of Waspaloy is measured when the travel length is $282 \mathrm{~mm}, 564 \mathrm{~mm}, 846 \mathrm{~mm}, 1128 \mathrm{~mm}$, and $1410 \mathrm{~mm}$ for each set of the cutting parameters. In addition to the tool wear and surface roughness at each travel length, Table 3 also lists the theoretical surface roughness for further discussion. The derivation of theoretical surface roughness is mentioned in surface roughness theory in (31). However, this theoretical surface roughness is described by the maximum surface roughness ( $R \max$ ), and the experiment applies the average surface roughness at the central line (Ra). Thus, the theoretical surface roughness shall be converted through the formula as follows [20]: 


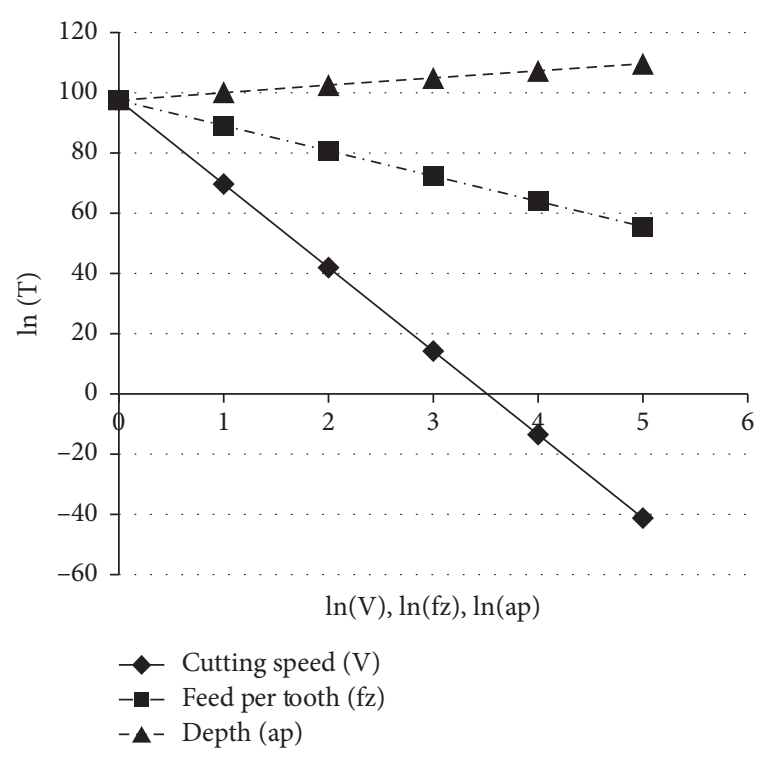

FIGURE 10: Impacts of cutting parameters on tool lifetime.

TABLE 3: Tool wear and surface roughness of Waspaloy for cutting parameters.

\begin{tabular}{|c|c|c|c|c|c|}
\hline $\begin{array}{l}t \text { group cutting } \\
\text { ters }\end{array}$ & \multicolumn{5}{|c|}{$\begin{array}{c}V=40 \mathrm{~m} / \mathrm{min}, \mathrm{fz}=0.3 \mathrm{~mm} / \text { tooth, } \\
\text { ap }=0.3 \mathrm{~mm}\end{array}$} \\
\hline $\begin{array}{l}\text { Theoretical surface roughness } \\
\text { (Ra) }\end{array}$ & \multicolumn{5}{|c|}{$0.469 \mu \mathrm{m}$} \\
\hline$T$ & 282 & 5 & 864 & 1128 & 1410 \\
\hline & & & 3 & & 0.00 \\
\hline & & & 0.325 & 0.729 & 0.48 \\
\hline The & \multicolumn{5}{|c|}{$\begin{array}{c}V=37.5 \mathrm{~m} / \mathrm{min}, \mathrm{fz}=0.35 \mathrm{~mm} / \\
\text { tooth, ap }=0.25 \mathrm{~mm}\end{array}$} \\
\hline $\begin{array}{l}\text { Theoretical surface roughness } \\
\text { (Ra) }\end{array}$ & \multicolumn{5}{|c|}{$0.638 \mu \mathrm{r}$} \\
\hline & & & & & 282 \\
\hline & & 142 & 0.142 & 142 & 0.142 \\
\hline - & 然 & 0.312 & 0.341 & 0.419 & 0.537 \\
\hline The & \multicolumn{5}{|c|}{$\begin{array}{c}V=35 \mathrm{~m} / \mathrm{min}, \mathrm{fz}=0.4 \mathrm{~mm} / \text { tooth}, \\
\mathrm{ap}=0.2 \mathrm{~mm}\end{array}$} \\
\hline cal surface roughne & \multicolumn{5}{|c|}{$0.833 \mu \mathrm{m}$} \\
\hline & & & 282 & 282 & 282 \\
\hline & 0.1 & 0.116 & 0.116 & 0.116 & 0.116 \\
\hline Surface roughn & 0.322 & 0.322 & 0.322 & 0.322 & 0.32 \\
\hline
\end{tabular}

$$
\mathrm{Ra}=\frac{1}{4} \mathrm{Rmax}
$$

where $\mathrm{Ra}$ is the average surface roughness at the central line and Rmax is the maximum surface roughness.

As shown in Table 3, for most of the sets of cutting parameters, the actual surface roughness is less than the theoretical one. The theoretical surface roughness can be defined as the surface roughness under conditions of a complete tool. For example, the first set of cutting parameters shall present the $0.469 \mu \mathrm{m}$ of the theoretical surface roughness at the $282 \mathrm{~mm}$ of the travel length, and the actual surface roughness is $0.297 \mu \mathrm{m}$ only. It shall be caused by the tool shape as shown in Figures 4 and 5 . Take $0.157 \mathrm{~mm}$ of tool wear at $282 \mathrm{~mm}$ of travel length for the first set of cutting parameter as an example; that is, $\mathrm{VB}$ is $0.157 \mathrm{~mm}$ of tool wear in Figure 11. Therefore, $a$ is $0.019 \mathrm{~mm}$ and $C 2$ is $0.954 \mathrm{~mm}$.

For the impacts of tool wear on the surface roughness, the relation between the tool wear and the surface roughness can be established based on the data in Table 4. For each set of the cutting parameters, the more tool wear will cause more surface roughness. However, the data at several experimental points is not in compliance with the trend. In addition to the tool wear, these symptoms may be caused by the tool adhesion, the cuttings which are not cleared and adhered on the workpiece surface, or other phenomena influencing the surface roughness of tool during the cutting.

If these experimental points are treated as noise and removed, the relation between tool wear and the surface roughness becomes linear as shown clearly in Figure 11, and the impacts of feed per tooth on the tool wear and surface roughness can be discovered. For each set of the cutting parameters, both of the impacts of cutting speed $(V)$ and the cutting depth (ap) are decreasing, and the impacts of the feed per blade are increasing. Moreover, under conditions of the same tool wear, the increased feed per tooth causes more surface roughness. Therefore, the three fitting curves approaching the experimental curves can be derived through the method of least squares and are shown in Table 4.

4.4. Tool Wear and Surface Roughness to Prediction. The research aims to predict that the surface roughness of workpiece after cutting meets the requirements or not in case of worn tool and how long such tool can be used subsequently. Based on the relations between the tool wear and surface roughness, the tool wear and the feed per tooth cause a certain influence on the surface roughness. Therefore, here assume a formula about the tool wear, the feed per tooth, and the surface roughness as follows [20]:

$$
a \times \mathrm{VB}+b \times \mathrm{fz}+c=\mathrm{SR} \text {. }
$$

The unknown values, $a, b$, and $c$, in formula (21) can be derived by substituting the results of the tool wear, the feed per tooth, and the surface roughness into formula (22) as follows:

$$
\left\{\begin{array}{c}
a \times \mathrm{VB}_{1}+b \times \mathrm{fz}_{1}+c=\mathrm{SR}_{1} \\
a \times \mathrm{VB}_{2}+b \times \mathrm{fz}_{2}+c=\mathrm{SR}_{2} \\
\vdots \\
a \times \mathrm{VB}_{n}+b \times \mathrm{fz}_{n}+c=\mathrm{SR}_{n}
\end{array}\right.
$$

Formula (23) can be described as the following matrix, where the experimental results of tool wear, feed per tooth, and surface roughness are

$$
\left[\begin{array}{ccc}
\mathrm{VB}_{1} & \mathrm{fz}_{1} & 1 \\
\mathrm{VB}_{2} & \mathrm{fz}_{2} & 1 \\
\vdots & \\
\mathrm{VB}_{n} & \mathrm{fz}_{n} & 1
\end{array}\right]\left[\begin{array}{l}
a \\
b \\
c
\end{array}\right]=\left[\begin{array}{c}
\mathrm{SR}_{1} \\
\mathrm{SR}_{2} \\
\vdots \\
\mathrm{SR}_{n}
\end{array}\right] .
$$




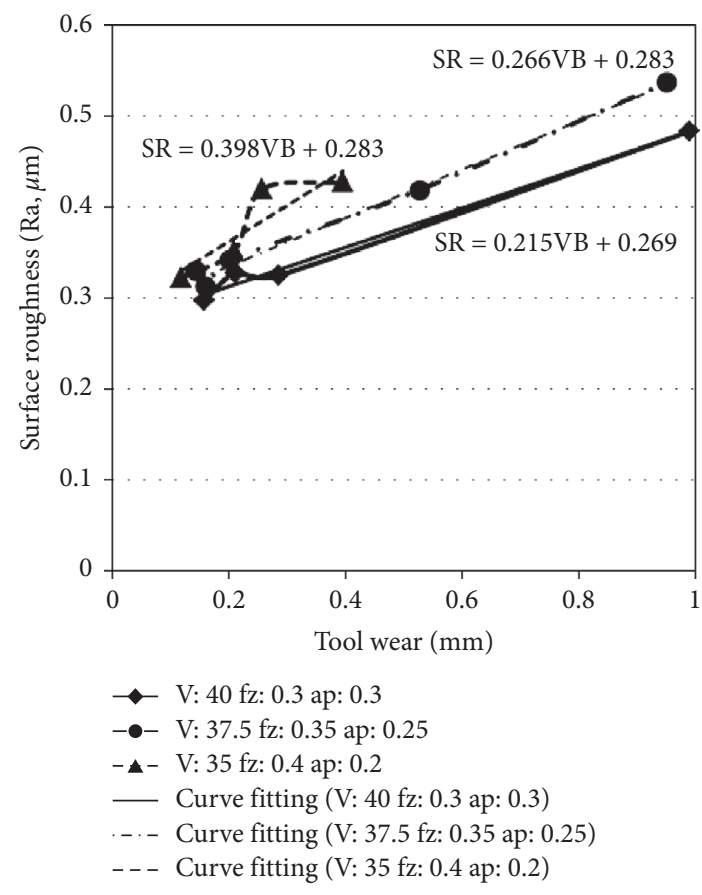

FIGURE 11: Relation between tool wear and surface roughness.

TABLE 4: Linear formula of tool wear on surface roughness, where SR is the surface roughness ( $\mathrm{Ra}, \mu \mathrm{m})$ and VB is the tool wear $(\mathrm{mm})$.

\begin{tabular}{lc}
\hline Cutting parameters & Linear formula \\
\hline$V=40 \mathrm{~m} / \mathrm{min}, \mathrm{fz}=0.3 \mathrm{~mm} /$ tooth, & $\mathrm{SR}=0.215 \mathrm{VB}+0.269$ \\
$\mathrm{ap}=0.3 \mathrm{~mm}$ & $\mathrm{SR}=0.266 \mathrm{VB}+0.282$ \\
$V=37.5 \mathrm{~m} / \mathrm{min}, \mathrm{fz}=0.35 \mathrm{~mm} /$ tooth, & \\
ap $=0.25 \mathrm{~mm}$ & $\mathrm{SR}=0.398 \mathrm{VB}+0.283$ \\
$V=35 \mathrm{~m} / \mathrm{min}, \mathrm{fz}=0.4 \mathrm{~mm} /$ tooth, & \\
ap $=0.2 \mathrm{~mm}$ &
\end{tabular}

Solving the above matrix can derive $a=0.248, b=0.633$, and $c=0.067$; then substitute these values into formula (22) as follows:

$$
0.248 \mathrm{VB}+0.633 \mathrm{fz}+0.067=\mathrm{SR} .
$$

By substituting the experimental results of the feed per tooth and the tool wear into formula (25) and drawing it as shown in Figure 12, it presents a corresponding trend line for each feed per tooth. Therefore, the predictive value of surface roughness after cutting can be derived after measuring the tool wear and substituting the value and the given feed per tooth into formula (25). Also, the predictive value of surface roughness can be used to determine the tool can be used subsequently or not. Table 5 shows the comparison for the experimental predictive surface roughness for each set of the cutting parameters.

4.5. Tool Wear and Cutting Time to Prediction. If the tool can be used in the cutting process subsequently, the next issue is how long the tool can be used subsequently. The cutting time, including the tool lifetime, is relative to the tool wear,

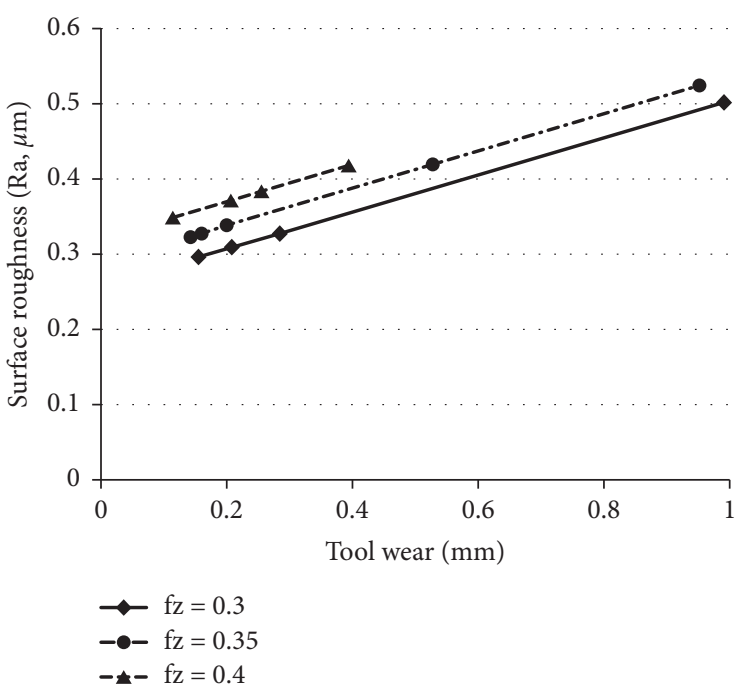

Figure 12: Trend of surface roughness prediction.

and the relation can be presented with a curve. Therefore, a formula of curve can be assumed to describe the relation between the cutting time and the tool wear as follows [20]:

$$
\begin{aligned}
A \times e^{B t} & =\mathrm{VB}, \\
t & =\frac{1}{B} \times \ln \left(\frac{\mathrm{VB}}{A}\right) .
\end{aligned}
$$

$A$ and $B$ in formula (27) are the factors influencing the formula of curve, and the values of $A$ and $B$ may be not the same under different cutting conditions as the fitting curve formula for each set of the cutting parameters. These results are listed in Table 6.

Since the $A$ and $B$ may be different with the set of cutting parameters, assume the $A$ and $B$ are relative to the cutting speed, the feed per tooth and the cutting depth as follows:

$$
\begin{aligned}
& \left\{V^{a 1} \times \mathrm{fz}^{b 1} \times \mathrm{ap}^{c 1}=A,\right. \\
& \left\{V^{a 2} \times \mathrm{fz}^{b 2} \times \mathrm{ap}^{c 2}=B .\right.
\end{aligned}
$$

Formula (28) shows the relation of $A$ to the cutting parameters, where $a 1, b 1$, and $c 1$ are unknown values and impact on $A$. $A$ can be derived by the following procedure:

$$
V^{a 1} \times \mathrm{fz}^{b 1} \times \mathrm{ap}^{c 1}=A \text {. }
$$

Practicing the logarithm in the above formula can derive the following one:

$$
a 1 \times \ln (V)+b 1 \times \ln (f z)+c 1 \times \ln (a p)=\ln (A) .
$$

Substitute the corresponding values of A for each set of the cutting parameters into the above formula (e.g., $A_{1}=0.084, A_{2}=0.066$, and $\left.A_{3}=0.081\right)$ :

$$
\left\{\begin{array}{l}
a 1 \times \ln \left(V_{1}\right)+b 1 \times \ln \left(\mathrm{fz}_{1}\right)+c 1 \times \ln \left(\mathrm{ap}_{1}\right)=\ln \left(A_{1}\right) \\
a 1 \times \ln \left(V_{2}\right)+b 1 \times \ln \left(\mathrm{fz}_{2}\right)+c 1 \times \ln \left(\mathrm{ap}_{2}\right)=\ln \left(A_{2}\right) \\
a 1 \times \ln \left(V_{3}\right)+b 1 \times \ln \left(\mathrm{fz}_{3}\right)+c 1 \times \ln \left(\mathrm{ap}_{3}\right)=\ln \left(A_{3}\right) .
\end{array}\right.
$$


TABLE 5: Comparison for the experimental and predictive surface roughness for each set of the cutting parameters.

\begin{tabular}{lcccc}
\hline The first group cutting parameters & \multicolumn{3}{c}{$V=40 \mathrm{~m} / \mathrm{min}, \mathrm{fz}=0.3 \mathrm{~mm} /$ tooth, ap $=0.3 \mathrm{~mm}$} \\
Experimental value $(\mu \mathrm{m})$ & 0.297 & 0.328 & 0.325 & 0.412 \\
Predictive value $(\mu \mathrm{m})$ & 0.295836 & 0.308980 & 0.327580 & 0.429 \\
Error $(\%)$ & 0.392 & 5.799 & 0.794 & 1.7 \\
\hline The second group cutting parameters & & $V=37.5 \mathrm{~m} / \mathrm{min}, \mathrm{fz}=0.35 \mathrm{~mm} /$ tooth, ap $=0.25 \mathrm{~mm}$ \\
Experimental value $(\mu \mathrm{m})$ & 0.330 & 0.330 & 0.330 & 0.330 \\
Predictive value $(\mu \mathrm{m})$ & 0.323766 & 0.323766 & 0.323766 & 0.323766 \\
Error $(\%)$ & 1.889 & 1.889 & 1.889 & 0.330 \\
The third group cutting parameters & & $V=35 \mathrm{~m} / \mathrm{min}, \mathrm{fz}=0.4 \mathrm{~mm} /$ tooth, ap = & $0.2 \mathrm{~mm}$ \\
Experimental value $(\mu \mathrm{m})$ & 0.322 & 0.332 & 0.351 & 0.420 \\
Predictive value $(\mu \mathrm{m})$ & 0.348968 & 0.315 & 0.371536 & 0.383688 \\
Error $(\%)$ & 8.375 & 1.7 & 5.851 & 0.427 \\
\hline
\end{tabular}

TABLE 6: Fitting curve formula of each set of cutting parameter on the cutting time.

Cutting parameters Curve formula

$V=40 \mathrm{~m} / \mathrm{min}, \mathrm{fz}=0.3 \mathrm{~mm} /$ tooth, and ap $=0.3 \mathrm{~mm}$ $\mathrm{VB}=0.084 \times e^{0.157 t}$

$V=37.5 \mathrm{~m} / \mathrm{min}, \mathrm{fz}=0.35 \mathrm{~mm} /$ tooth, and ap $=0.25 \mathrm{~mm}$ $\mathrm{VB}=0.066 \times e^{0.177 t}$

$V=35 \mathrm{~m} / \mathrm{min}, \mathrm{fz}=0.4 \mathrm{~mm} /$ tooth, and ap $=0.2 \mathrm{~mm}$ $\mathrm{VB}=0.081 \times e^{0.119 t}$

TABLe 7: Comparison for the experimental and predictive cutting time for each set of the cutting parameters.

\begin{tabular}{|c|c|c|c|c|c|}
\hline The first group cutting parameters & \multicolumn{5}{|c|}{$V=40 \mathrm{~m} / \mathrm{min}, \mathrm{fz}=0.3 \mathrm{~mm} /$ tooth, $\mathrm{ap}=0.3 \mathrm{~mm}$} \\
\hline Experimental value (min) & 3.133 & 6.267 & 9.4 & 12.533 & 15.667 \\
\hline Predictive value (min) & 3.992036 & 5.845427 & 7.791341 & 13.705577 & 15.719503 \\
\hline Error $(\%)$ & 27.419 & 6.727 & 17.113 & 9.356 & 0.335 \\
\hline Average magnitude of error (\%) & \multicolumn{5}{|c|}{12.190} \\
\hline The second group cutting parameters & \multicolumn{5}{|c|}{$V=37.5 \mathrm{~m} / \mathrm{min}, \mathrm{fz}=0.35 \mathrm{~mm} /$ tooth, $\mathrm{ap}=0.25 \mathrm{~mm}$} \\
\hline Experimental value (min) & 3.82 & 5.64 & 7.46 & 11.28 & 14.1 \\
\hline Predictive value (min) & 4.335873 & 4.974936 & 6.271479 & 11.736453 & 15.077437 \\
\hline Error $(\%)$ & 13.5 & 11.792 & 15.95 & 4.047 & 6.932 \\
\hline Average magnitude of error (\%) & & & 10.4458 & & \\
\hline The third group cutting parameters & \multicolumn{5}{|c|}{$V=35 \mathrm{~m} / \mathrm{min}, \mathrm{fz}=0.4 \mathrm{~mm} /$ tooth, $\mathrm{ap}=0.2 \mathrm{~mm}$} \\
\hline Experimental value (min) & 2.564 & 5.127 & 7.691 & 10.255 & 12.818 \\
\hline Predictive value (min) & 3.027042 & 4.607661 & 7.894739 & 9.680498 & 13.283241 \\
\hline Error $(\%)$ & 18.059 & 10.129 & 2.649 & 5.602 & 3.630 \\
\hline Average magnitude of error (\%) & & & 8.014 & & \\
\hline
\end{tabular}

Then, solving the matrix of the above formula can derive $a 1=-5.666, b 1=-10.095$, and $c 1=-5.207$. Then, solving the matrix of the above formula can derive $a 2=5.191$, $b 2=10.804$, and $c 2=6.639$. Finally, substitute the values, $a 1$, $a 2, b 1, b 2, c 1$, and $c 2$, into formulas (28) and (29) to derive the prediction formula as follows:

$$
\begin{aligned}
& \left\{t=\frac{1}{B} \times \ln \left(\frac{\mathrm{VB}}{A}\right),\right. \\
& \left\{V^{-5.666} \times \mathrm{fz}^{-10.095} \times \mathrm{ap}^{-5.207}=A,\right. \\
& \left\{V^{5.191} \times \mathrm{fz}^{10.804} \times \mathrm{ap}^{6.639}=B .\right.
\end{aligned}
$$

Summarily, there are two sets of derived formulas. The first set, formula (25), can predict the feasibility of a won tool in the cutting process. The second set, formulas (32)-(34), can predict the residual cutting time of such worn tool. Tables 5 and 6 show the comparison for the experimental predictive cutting time for each set of the cutting parameters. For example, practicing a cutting process with the first set of cutting parameter, the cutting speed $(V)=40 \mathrm{~m} / \mathrm{min}$, the feed per tooth $(\mathrm{fz})=0.3 \mathrm{~mm} /$ tooth, the cutting depth $(\mathrm{ap})=$ $0.3 \mathrm{~mm}$, and the given tool wear $(\mathrm{VB})=0.157 \mathrm{~mm}$; then the surface roughness and the residual cutting time can be derived as follows.

Substitute the tool wear (VB) and the feed per tooth (fz) into formula (24):

$$
\begin{aligned}
& 0.248 \mathrm{VB}+0.633 \mathrm{fz}+0.067=\mathrm{SR} \\
& \mathrm{SR}=0.248 \times 0.157+0.633 \times 0.3+0.067=0.296(\mu \mathrm{m}) .
\end{aligned}
$$

Solving the above formulas can derive the surface roughness $(\mathrm{SR})=0.296 \mu \mathrm{m}$ at the tool wear $(\mathrm{VB})=$ $0.157 \mathrm{~mm}$. The result can be used to determine the surface roughness processed by the tool meets the requirement or not. If the tool is available, substitute the cutting speed $(V)=$ $40 \mathrm{~m} / \mathrm{min}$, the feed per tooth $(\mathrm{fz})=0.3 \mathrm{~mm} /$ tooth, and the cutting depth (ap) $=0.3 \mathrm{~mm}$ into formulas (33) and (34) and 
derive the influence factors of the predictive formula of cutting time, $\mathrm{A}$ and $\mathrm{B}$ :

$$
\begin{aligned}
A= & V^{-5.666} \times \mathrm{fz}^{-10.095} \times \mathrm{ap}^{-5.207}=40^{-5.666} \times 0.3^{-10.095} \\
& \times 0.3^{-5.207}=0.084 \\
B= & V^{5.191} \times \mathrm{fz}^{10.804} \times \mathrm{ap}^{6.639}=40^{5.191} \times 0.3^{10.804} \times 0.3^{6.639} \\
= & 0.157 .
\end{aligned}
$$

Substitute the derived A and B into formula (33) to derive the predictive formula of cutting time as follows:

$$
t=\frac{1}{0.157} \times \ln \left(\frac{\mathrm{VB}}{0.084}\right)
$$

Substitute the tool wear $(\mathrm{VB})=0.157 \mathrm{~mm}$ into the above formula to derive the time of the tool used under the given cutting parameters. Assume the tool is unavailable at the tool wear $(\mathrm{VB})=0.3 \mathrm{~mm}$ or more. Then, the cutting time at the tool wear $(\mathrm{VB})=0.3 \mathrm{~mm}$ can be derived. By subtracting the cutting time at the tool wear $(\mathrm{VB})=$ $0.157 \mathrm{~mm}$ from the cutting time at tool wear $(\mathrm{VB})=$ $0.3 \mathrm{~mm}$, the residual time of the tool can be derived as 4.124 ( $\mathrm{min})$, as shown in Table 7.

\section{Conclusion}

(1) Tool wear curve: based on the experiments of the first and the second sets of cutting parameters, the tool wear is significant after the cutting time is more than 9 minutes. Since the tool wear can be divided into three stages, namely, the burst stage, the stable stage, and the damage stage, the significant tool wear is caused that the tool wear has exceeded the stable stage and reached the damage stage.

(2) Factors impacting tool lifetime: according to the experimental results, the impacts of the cutting speed on the tool lifetime are the most significant, and the impacts of the cutting depth on the tool lifetime are the least. The experimental results are similar to most of research results. In addition, the impacts of the feed per tooth on the surface roughness are more, followed by the impacts of the tool wear.

(3) Comparison of experimental and predicted surface roughness: in the prediction of surface roughness, the maximum error between the actual value and the predicted value for the first set of cutting parameters is $5.799 \%$, this for the second set of cutting parameters is $5.122 \%$, and this of the third set of cutting parameters is $8.375 \%$.

(4) Comparison of experimental and predicted cutting time: in the prediction of cutting time, the average magnitude of error between the actual value and the predicted value for the first set of cutting parameters is $12.19 \%$, this for the second set of cutting parameters is $10.4458 \%$, and this of the third set of cutting parameters is $8.014 \%$.

\section{Nomenclature}

$V:$
VB:
Ap:
$H:$
Ci:

T:

Fz:

SR: and $c 2$ :

A, B: $a 1, a 2, b 1, b 2, c 1$,
Cutting speed $(\mathrm{m} / \mathrm{min})$

Tool wear $(\mathrm{mm})$

Cutting depth (mm)

Cutting thickness (fixed value: $0.1 \mathrm{~mm}$ )

Diameter of throwaway tool (fixed

value: $12 \mathrm{~mm}$ )

Cutting time ( $\mathrm{min})$

Feed per tooth (mm/tooth)

Surface roughness $(\mathrm{Ra}, \mu \mathrm{m})$

Constant values

Influence factors
The experimental results of tool wear $(\mathrm{mm})$

$\mathrm{fz} \_1, \quad$ Experimental results of feed per tooth

$\mathrm{fz} \_2, \ldots, \mathrm{fz} \_n: \quad(\mathrm{mm} /$ tooth $)$

SR_1, Experimental results of surface roughness

SR_2,..,SR_n: (Ra, $\mu \mathrm{m})$.

\section{Data Availability}

The raw/processed data required to reproduce these findings cannot be shared at this time as the data also form part of an ongoing study.

\section{Conflicts of Interest}

The authors declare that they have no conflicts of interest.

\section{References}

[1] F. Campbell, "Chapter 6-superalloys," in Manufacturing Technology for Aerospace Structural Materials, F. Campbell, Ed., pp. 211-272, Elsevier Science, Oxford, MI, USA, 2006.

[2] E. O. Ezugwu, Z. M. Wanga, and R. Machado, "The machinability of nickel-based alloys: a review," Journal of Materials Processing Technology, vol. 86, no. 1-3, pp. 1-16, 1999.

[3] R. Polvorosa, A. Suárez, L. N. L. de Lacalle, I. Cerrillo, A. Wretland, and F. Veiga, "Tool wear on nickel alloys with different coolant pressures: comparison of Alloy 718 and Waspaloy," Journal of Manufacturing Processes, vol. 26, pp. 44-56, 2017.

[4] S. Hanasaki, J. Fujiwara, M. Touge, Y. Hasegawa, and K. Uehara, "Tool wear of coated tools when machining a high nickel alloy," CIRP Annals, vol. 39, no. 1, pp. 77-80, 1990.

[5] M. Nalbant, A. Altın, and H. Gökkaya, "The effect of cutting speed and cutting tool geometry on machinability properties of nickel-base Inconel 718 super alloys," Materials \& Design, vol. 28, no. 4, pp. 1334-1338, 2007.

[6] A. Jawaid, S. Koksal, and S. Sharif, "Cutting performance and wear characteristics of PVD coated and uncoated carbide tools in face milling Inconel 718 aerospace alloy," Journal of Materials Processing Technology, vol. 116, no. 1, pp. 2-9, 2001.

[7] M. Zetek, I. Česáková, and V. Švarc, "Increasing cutting tool life when machining Inconel 718," Procedia Engineering, vol. 69, pp. 1115-1124, 2014.

[8] S. H. Wang and Y. L. Su, Tribology Potential of DLC Coated Milling Inserts, National Cheng Kung University the Degree of Master, Tainan, Taiwan, 1998. 
[9] C. T. Sims and W. Hagel, The Superalloys, Wiley-Interscience, New York, NY, USA, 1972.

[10] H. Bhadeshia, Nickel Based Super-alloys, University Of Cambridge, Cambridge, England, 2002.

[11] H.-Y. Bor, A Study on the Elevated Temperature Brittleness and Fracture Mechanism of Mar-M247 Superalloy, National Chiao Tung University the Degree of Master, Hsinchu, Taiwan, 1998.

[12] B. H. Kear, J. M. O'blak, and A. F. Giami, "Stacking faults in gamma prime precipitation hardened nickel-base alloys," Metallurgical Transacions, vol. 1, pp. 2477-2486, 1970.

[13] C. M. Hong, Z. H. Yao, M. C. Zhang, J. X. Dong, and Y. F. Zhang, "The thermodynamic calculation of Waspaloy alloy carbide and $\gamma^{\prime}$ phase precipitation law," Journal of University of Science and Technology Beijing, vol. 30, no. 9, pp. 1018-1023, 2008.

[14] A. S. Abdulhakim and A. C. Okafor, "Effects of geometric parameters of wavy-edge bull-nose helical end-mill on cutting force prediction in end-milling of Inconel 718 under MQL cooling strategy," Journal of Manufacturing Processes, vol. 23, pp. 102-114, 2016.

[15] S. H. Chen, "Study on application of grey prediction model in superalloy MAR-247 machining," Advances in Materials Science and Engineering, vol. 2015, Article ID 704143, 10 pages, 2015.

[16] S. H. Chen and Yu-L. Ho, "Lifespan of super-alloy Waspaloy cutting tools," Heliyon, vol. 5, no. 4, Article ID e01388, 2018.

[17] P. Nieslony, G. M. Krolczyk, S. Wojciechowski, R. Chudy, K. Zak, and R. W. Maruda, "Surface quality and topographic inspection of variable compliance part after precise turning," Applied Surface Science, vol. 434, pp. 91-101, 2018.

[18] R. W. Maruda, G. M. Krolczyk, S. Wojciechowski, K. Zak, W. Habrat, and P. Nieslony, "Effects of extreme pressure and anti-wear additives on surface topography and tool wear during MQCL turning of AISI 1045 steel," Journal of Mechanical Science and Technology, vol. 32, no. 4, pp. 1585-1591, 2018.

[19] S. E. Oraby and D. R. Hayhurst, "Tool life determination based on the measurement of wear and tool force ratio variation," International Journal of Machine Tools and Manufacture, vol. 44, no. 12-13, pp. 1261-1269, 2004.

[20] C. A. Yu and S. H. Chen, The Prediction of Tool Life in Milling Waspaloy, NCUT the Degree of Master, Taichung, Taiwan, 2016. 